perfusion, and consequent disability, without reducing the FEV. Therefore disability produced by simple pneumoconiosis may not only be masked by an unequal distribution of chronic bronchitis, but the tests that have been relied on to look for it are particularly insentitive.

This argument may be rejected because there is little or no evidence that chronic bronchitis is less common in miners with higher categories of simple pneumoconiosis than in those without. Because, during life, chronic bronchitis has to be diagnosed on the presence of symptoms and because it has been convincingly shown ${ }^{4}$ that simple pneumoconiosis itself produces the same symptoms (even when smoking habits are taken into account) there are enormous difficulties in determining the distribution of chronic bronchitis in miners. The same investigation ${ }^{4}$ showed that the presence of simple pneumoconiosis was associated strongly with a complaint of breathlessness. This again would be expected with small-airways or alveolar disease and this seems a more logical explanation than an assumption that the men complained of breathlessness because many were aware that they had pneumoconiosis.

Satisfactory information about the distribution of chronic bronchitis in miners can probably come only from careful postmortem bronchial histology. Some attempt at this was made by Lyons et al..$^{5}$ but their series did not include enough subjects without pneumoconiosis to achieve valid conclusions. I have a very strong clinical impression that severe chronic bronchitis, characterized by the "blue bloater," is seldom if ever seen in a man with category 3.

Unequal distribution of chronic bronchitis may also conceal a reduction in life expectancy due to simple pneumociosis. Dr. Cochrane's table III gives a little support for this view. Below the age of 45 there is somewhat higher mortality in men with simple pneumoconiosis. In these younger men there should be less bronchitis and thus less "protection" from the development of pneumoconiosis. Mortality would then be a better reflection of the effect of simple pneumoconiosis. Between 45 and 65 years mortality is considerably higher in men with category $\mathbf{O}$ than in those with simple pneumoconiosis and this may be due to an excess of bronchitis in the former group.

I believe Dr. Cochrane's conclusions should be qualified by adding that the distribution of ohronic bronchitis in miners is probably uneven. Because of the marked effect this has on conventional ventilatory tests and on mortality, uneven distribution may well mask substantial disability and mortality produced by higher categories of simple pneumoconiosis. As someone who tries to avoid being emotionally stirred by a number of dots on $x$-rays, I still find it impossible, when looking at microscopical and paper-mounted sections of lungs with extensive simple pneumoconiosis, to believe that it has no significant effect on a man's capacity to breathe comfortably and to live to an old age. There are, of course, other ways in which simple pneumoconiosis can produce disability ${ }^{5-7}$ which have not been touched on here or by Dr. Cochrane.-I am, etc.,

Dewi Davies

Ransom Hospital,

Ransom Hospita,
near Marths,

\begin{tabular}{|c|c|c|c|c|c|}
\hline & \multirow{2}{*}{$\begin{array}{l}\text { Non- } \\
\text { Miners }\end{array}$} & \multicolumn{4}{|c|}{ Miners } \\
\hline & & Cat. 0 & Cat. 1 & $\overline{\text { Cat. } 2}$ & Cat. 3 \\
\hline Numb & 100 & 100 & 100 & 100 & 100 \\
\hline $\begin{array}{l}\text { bronchitis .. } \\
\text { Ventilatory } \\
\text { score for }\end{array}$ & 20 & 45 & 40 & 25 & 10 \\
\hline $\begin{array}{l}\text { non- } \\
\text { bronchitics } \\
\text { Ventilatory }\end{array}$ & 8,400 & 5,500 & 5,700 & 6,750 & 7,650 \\
\hline $\begin{array}{l}\text { score for } \\
\text { bronchitics }\end{array}$ & 1,400 & 3,150 & 2,600 & 1,500 & 550 \\
\hline $\begin{array}{l}\text { 10tal } \\
\text { ventilatory.. } \\
\text { score }\end{array}$ & 9,400 & 8,650 & 8,300 & 8,250 & 8,200 \\
\hline
\end{tabular}

1 Lippman, M., Albert R. B., and Peterson, H. T., in British Occupational Hygiene Society, Symposium on Inhaled Particles, 1901.

2 Cochrane, A. L., Hriggins, II.T. T.; and Thomas Medicine, 1961, 15, 1 .

3 Seaton, A., Thorax, 1973, 28, 267.

Ashford, J. R., Morgan, D. C.., Rae, S., and Sowden, R. R., American Review of Respiratory Diseases, 1970, 102, 370

5 Lyons, J. P., Ryder, R., Campbell, $H$. ., and Gough, J., British Medical Youmnal, Cotes, J. B., British Medical fournal, 1967, 4, $7 \begin{aligned} & \text { Morgan, W. K. C., Burgess, D. B., Lapp, N. L., } \\ & \text { and Seaton, A., Thorax, 1971, } 26.585 \text {. }\end{aligned}$

\section{Prodromal Symptoms of Biliary Colic or} Cholecystitis

SIR,-Prodromal symptoms are such as may occur in the time immediately preceding a more serious disease. On 3 and 4 April 1969 I suffered an acute attack of cholecystitis for which the gall-bladder was successfully removed. During the six months preceding this acute attack I had suffered some symptoms which puzzled me and my doctor and which I mentioned in a short article published in the B.M.J. (18 July 1970, p. 147).

These prodromal symptoms occurred at intervals of one to three weeks. The first attack was in about September 1968. I had got to sleep about ten o'clock and woke suddenly a few hours later; I had no pain but I was sweating profusely and my heart was beating about twice its normal rate. I sat up in bed wondering what had caused these symptoms, but since they gradually subsided I took little notice of them. But soon they became frequent enought to cause me to have a towel by my bedside to dry myself if an attack occurred. My doctor examined me thoroughly but could find no cause for the symptoms, but on the night of 9-10 February 1969 I had a more severe attack and rang the bell to my sister's room (she is a qualified nurse) and since I was unable to get on the telephone to my own doctor I phoned my sisters' doctor, who gave me good advice, told me to take my usual hypnotic, and the attack passed off. There was no pain at any time, but the awakening was so sudden that it must have been due to some unascertainable cause.

Then on 3 April I had the acute attack of cholecystitis which I described in my published account. The gall-bladder was already necrotic in some places and when it was removed and opened was found to contain 15 pigmented gall-stones (black pigment). There was no stone which could possibly have passed into the cystic duct but all the stones were irregular in shape and rather flattened, and two of them had each of them at one end a smooth rounded quarter-inch that made it quite certain that they had attempted to enter the cystic duct. Neither of them could have got far into the duct but I came to the conclusion that their attempted entry into the duct may have been the direct cause of the sweating and the increase in heart rate. At the same time I could not with assurance say that they had caused the symptoms and I have waited four years before I give it my opinion that my suggestion was correct, for I have not had any similar attack since the operation was performed.

It is well known that reflexes from the gall-bladder can cause symptoms which can call attention to the heart rather than the gall-bladder and copious sweating could easily be caused reflexly through the sympathetic nerves. The absence of pain can be explaind by the fact that I sat up immediately when awakened and the stone would at once fall away from the neck of the gall-bladder. I have never seen any reference to similar prodromal attacks, nor have I heard any mention of them, so they are either very rare or have been overlooked. I am writing this note so that the readers of the B.M.J. may be on the look out for any such similar prodromal symptoms.-I am, etc.,

Oxford

V. ZAchaRY COPE

\section{The Problem Oriented Medical Record}

SIR,-One of the major benefits of Professor Lawrence Weed's system of problem oriented medical records which was described by Dr. Neil McIntyre (9 June, p. 598) is the structuring of the clinical data which ensues from it. As the structuring of data is one of the more difficult parts of the design of any system for making inter-patient comparisons, particularly if a computer is involved, it is not surprising to find that one has been used as a vehicle for Professor Weed's record.

May I appeal to those interested in this system, however, not to associate too closely the ideas of problem oriented medical records and the use of a computer to collect and process these records. As you say in your leading article in the same issue ( 9 June, $p$. 570), a lot of research is still needed in the application of computing techniques in medicine. Professor Weed's ideas can undoubtedly be applied with great benefit to existing medical data; and should a successful system "pencil and paper" methods of recording of computer-based problem oriented records not be achieved as rapidly as we would wish, it is important that the potential benefits of the problem oriented approach should not be discarded because of difficulties inherent in the application of today's technology in medical environments.-I am, etc.,

E. C. COLes

Division of Computing and Statistics,

Clinical Research Centre,
Harrow, Middlesex

\section{Hospital Medicine Sheets}

SIR,-It is surprising that atter 20 years of the National Health Service no standard form of hospital medicine prescription sheet has become generally acceptable and applicable.

At the present time different hospital groups, and their separate hospitals in some instances, have their own specially designed and printed sheets. This involves unnecessary 
expenditure, but more serious is the risk of confusion and error in the case of nurses handling prescription cards with which they may be unfamiliar. Today hospital medicine sheets are used by nurses at each medicine round and need to be devised with due consideration to the work of the nurse in addition to the preferences of the doctor and the pharmacist.

Reasonable rules, regulations, and recommendations about prescription sheets in hospitals have come from various bodies, and the desirable features these sheets should incorporate are no longer subjects of controversy, debate, or individual whim. For many years the armed Services have operated with a standard system of medical records which, being already in existence, is used without objection. It is questionable whether civilian practice can continue to afford the doubtful luxury of indulging idiosyncrasies in a matter on which the life and death of a patient may depend.-I am, etc.,

\section{A. SPENCER}

Meanwood Park Hospital,
Leeds

\section{Bronchospasm following Althesin} Anaesthesia

SIR,-I should like to comment on the letter from Lt. Col. T. R. Austin and others (16 May, p. 661) implicating Althesin as the causative factor in producing bronchospasm in a patient, following induction of anaesthesia. While I agree that such a reaction to any anaesthetic agent should be brought to the attention of an investigating body, 1 perhaps they should have looked at their case a little more closely to discover whether it was Althesin or, in fact, pancuronium that induced the bronchospasm.

Examining in a little more detail the three anaesthetics that their patient received, it seems that pancuronium was just as likely as Althesin to have induced the bronchospasm in the course of the second anaesthetic. The first anaesthetic was uneventful, though both thiopentone and suocinylcholine can induce bronchospasm in susceptible patients. 2 Here alcuronium was used for relaxation. Alcuronium is practically devoid of histamine release (and bronchospasm) in ordinary dosage. ${ }^{3}$ The third anaesthetic was uneventful. Thiopentone had already been used without production of bronchospasm, and the $\mathrm{N}-\mathrm{O}_{2}-\mathrm{O}_{2}$-halothane sequence is not associated with the production of bronchospasm. For the second anaesthetic both Althesin and pancuronium were used, and though the patient coughed and bucked on the endorracheal tube following intubation this "rapidly settled," but "over the next few minutes the lungs became more and more difficult to inflate." An increment of pancuronium was then given and soon the diagnosis of bronchospasm was made. In three out of five cases of bronchospasm following $\mathrm{Al}$ thesin reported by Avery and Evans," and in the case reported by Hester, ${ }^{\mathrm{b}}$ onset of bronchospasm following Althesin was almost instantaneous. I wonder what contribution, if any, the additional dose of pancuronium made to the developing bronchospasm in the case reported by Lt. Col. Austin and his colleagues.

Buckland and Avery' reported the case of an asthmatic patient who appears to have developed bronchospasm after being given pancuronium (without Althesin), and they demonstrated a moderate skin weal following subcutaneous sensitivity testing with pancuronium. Would sensitivity testing with both Althesin and pancuronium help to identify the causative drug in the patient described by Lt. Col. Austin and his colleagues, especially as this patient may require further anaesthetics some time in the future? I should be very pleased to hear their views and comments.-I am, etc.,

\section{J. Heslop}

Norfolk and Norwich Hospital

1 Dundee, J. W., and Clarke, R. S. J., British Fourmal of Anaesthesia, 1973, 45, 304

coodman, L. S., and Gillman, A.; The Pharmacological Basis of Therapeutics,

Lund. I., and Stovner, J., Acta Anaesthesiologica, Scandinavica, 1962, 685 .

Avery, A. F., and Evans, A., British Foumal of Anaesthesia, 1973, 45, 301

Hester, J. B., British Foumal of Anaesthesia, 1973,

6 Buckland, R. W., and Avery, A. F., British foumal of Anaesthesia, 1973, 45, 518. 37, 540 .
H., British Fourmal of Anaesthesia, 1965,

SIR,-It is a pity that the case of bronchospasm "following Althesin anaesthesia" reported by Lt. Col. T. R. Austin and others (16 June, p. 661) should have had such a complex pharmacological history. However, it does appear that bronchosparm is a potential hazard with this anaesthetic agent, and I would like to report the following slightly more straightforward case.

A $65-\mathrm{kg}$ man was given Althesin for extraction of two molars without any complications. Ten weeks later he was again anaesthetized for removal of two more molars ucing Althesin via a "Butterfly" needle in the back of his hand. He had confirmed that he had had no reaction to the previous anaesthetic, was in his usual good health, was not taking any other drugs, and had been given no premedication or muscle relaxant.

After $2.5 \mathrm{ml}$ of Althesin had been given slowly he coughed several times and was then noted to be experiencing rapidly increasing dyspnoea due to easily audible bronchospasm. Althesin was discontinued and he was given oxygen and then aminophylline $250 \mathrm{mg}$ and hydrocortisone $50 \mathrm{mg}$ intravenously. Though he remained slightly cyanosed for two to three minutes, the bronchospasm settled quickly and by the time he regained consciousness about 10 minutes later he confirmed mild bronchospasm, but only after direct questioning. On further questioning he gave no history of any allergy or asthma. Within two hours he had no signs or symptoms and was allowed home. He has since remained well.

As was pointed out by the manufacturers he could have reacted to any of several components, and they are at present looking into his case.-I am, etc.,

Tewkesbury Glos.

A. N. CROWTHER

**Althesin contains alohadolone acetate $0.3 \% \mathrm{w} / \mathrm{v}$, alphaxolone $0.9 \% \mathrm{w} / \mathrm{v}$, Cremophor EL (a brand of polyethoxvlated cartor oil) $20 \% \mathrm{w} / \mathrm{v}$, and sodium chloride $0.25 \%$ w/v-ED. B.M.f.

\section{Portable Anaesthetic Machine}

SiR,-It was interesting to read that the Derbyshire Royal Infirmary Accident Flving Squad had developed a portable anaesthetic machine to take to the scene of an accident (31 March, p. 788). This field has been left surprisingly undeveloped for a long time, and so far little attention has been given to producing a more comprehensive unit to cover all possible anaesthetic needs at the site of an accident.

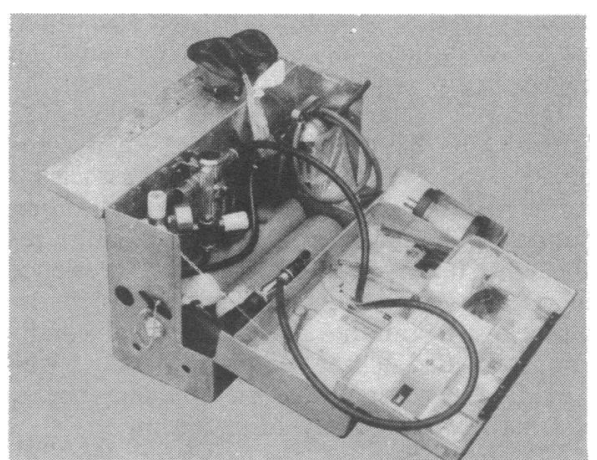

Recently, with the considerable help of the British Oxygen Co., Ltd., who provided numerous pieces of equipment, a useful apparatus has been made to my design which incorporates with the anaesthetic machine both an efficient suction apparatus and space for endotracheal tubes, instruments, drugs, syringes, etc. -all contained within a case measuring 24 in. $\times 14$ in. $\times 8 \frac{1}{2}$ in. $(61 \mathrm{~cm}$ $\times 36 \mathrm{~cm} \times 22 \mathrm{~cm}$ ). The gas used is Entonox, of which two cylinders of 5001 . are accommodated, and there is a halothane vaporizer; the sucker is powered by the Entonox gas and achieves a suction pressure of approximately $450 \mathrm{~mm} \mathrm{Hg}$. The whole weighs about $45 \mathrm{lb}(20 \mathrm{~kg}$ ), at present (about the weight of a laden suitcase) but, as the Derby workers have stated, considerable weightsaving could be achieved if lightweight cylinders were available for the gas.

In this way, the need for carrying several different pieces of equipment to the accident scene is removed and the means provided for resuscitation or for anaesthesia. This apparatus should be available shortly as it is being manufactured and marketed by Marden Medical Equipment Ltd., of 41 North Audley Street, London W.1.-I am, etc.,

Leatherhead, Surrey

KaTth ANDERSON

\section{Breech Management with Fetal Blood} Sampling

SIR,-We have been gratified to find that our recent paper on breech management (23 December, p. 703) has aroused such interest. A number of points were raised in the letters from various correspondent which we feel deserve comment, and, in some cases, clarification.

Mr. W. G. Mills (27 January, p. 229) brought up some interesting points, especially with regard to the passage of meconium. We agree that the passage of meconium early in the first stage is an indication for further investigation, and in our view this is best carried out by fetal blood sampling. Certainly in our experience the passage of meconium is not invariably associated with a low pH, although in two of the three cases in our series in which caesarean section was required for fetal distress in the first stage meconium was passed early in the labour. 